\title{
Adjuvants are key factors for the development of future vaccines: lessons from the Finlay adjuvant platform
}

\section{Oliver Pérez ${ }^{1,2}$ *, Belkis Romeu ${ }^{1}$ *, Osmir Cabrera ${ }^{1}$, Elizabeth González ${ }^{1}$, Alexander Batista-Duharte ${ }^{3}$, Alexis Labrada ${ }^{4}$, Rocmira Pérez $^{1}$, Laura M. Reyes ${ }^{1}$, Wendy Ramírez ${ }^{4}$, Sergio Sifontes $^{5}$, Nelson Fernández $^{6}$ and Miriam Lastre ${ }^{1}$}

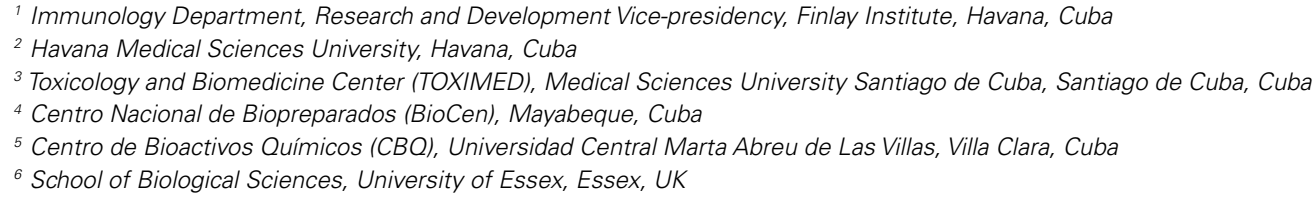

\section{Edited by:}

Virgil Schijns, Wageningen University, Netherlands

\section{Reviewed by:}

Val Ferro, University of Strathclyde, UK

Virgil Schijns, Wageningen University, Netherlands

*Correspondence:

Oliver Pérez and Belkis Romeu, Immunology Department, Research and Development Vice-presidency, Finlay Institute, Avenue 17 Esq 198, Siboney, Playa, P.O Box 16017, Havana 11600, Cuba e-mail: oliverp@finlay.edu.cu; bromeu@finlay.edu.cu
The development of effective vaccines against neglected diseases, especially those associated with poverty and social deprivation, is urgently needed. Modern vaccine technologies and a better understanding of the immune response have provided scientists with the tools for rational and safer design of subunit vaccines. Often, however, subunit vaccines do not elicit strong immune responses, highlighting the need to incorporate better adjuvants; this step therefore becomes a key factor for vaccine development. In this review we outline some key features of modern vaccinology that are linked with the development of better adjuvants. In line with the increased desire to obtain novel adjuvants for future vaccines, the Finlay Adjuvant Platform offers a novel approach for the development of new and effective adjuvants. The Finlay Adjuvants (AFs), AFPL (proteoliposome), and AFCo (cochleate), were initially designed for parenteral and mucosal applications, and constitute potent adjuvants for the induction of Th1 responses against several antigens. This review summarizes the status of the Finlay technology in producing promising adjuvants for unsolved-vaccine diseases including mucosal approaches and therapeutic vaccines. Ideas related to adjuvant classification, adjuvant selection, and their possible influence on innate recognition via multiple toll-like receptors are also discussed.

Keywords: adjuvant, vaccine, proteoliposome, cochleate, allergen, fish

\section{INTRODUCTION}

Since the systematization of vaccination principles by Louis Pasteur in 1886 and the introduction of the "triple I" (isolation, inactivation, and injection) concept, most vaccinologists have searched for specific antigens to be used as immunogens, with special emphasis on epitope identification. This approach has also aimed at reducing vaccine reactogenicity and hence increasing efficacy. Since early times (1), adjuvants have been considered a crucial vaccine component. Indeed, adjuvants play a key role in most new vaccine formulations and are used to enhance the efficacy of a particular preparation, even when different vaccines are prepared with identical antigens (2). Currently, several pharmaceutical companies use the aluminum-based mineral salts (Alum) as an adjuvant; which include three different aluminum salts: aluminum hydroxide, aluminum phosphate, and aluminum hydroxyphosphate (3). Alum is found in numerous vaccines, including diphtheria-tetanus-pertussis, human papillomavirus, influenza, and hepatitis vaccines (4), and most importantly, this adjuvant has an excellent health and safety track record (5). Alum provokes responses characterized by a predominance of immunoglobulin G 1 (IgG1) in mice and IgE (in mice and humans). Notably, however, Alum is known to be a poor adjuvant for the induction of cytotoxic T-cell immunity and T helper (Th) 1 immune responses, which are essential to combat several life-threatening infections. Thus, there is an urgent need to develop novel adjuvants to address the development of vaccines against pathogens that have so far been refractory to traditional vaccination strategies and to overcome the limitations of the few available licensed adjuvants $(3,6)$.

Recent advances in immunology and related disciplines such as genomics and proteomics have contributed enormously to the field of vaccinology and have permitted the rational design of adjuvants and their molecular characterization. An important advance has been the understanding as to how the innate immune system is able to "sense" and recognize molecules associated with specific families of microbes, termed microbe-associated molecular patterns (MAMP). This recognition occurs via a series of pattern-recognition receptors (PRRs), including toll-like receptors (TLRs), lectin-type receptors, and soluble cytoplasmic receptors (Nod-like receptors and retinoic acid inducible gene I-like receptors). The aim of this review is to discuss new ideas about vaccinology and adjuvant technology and to consider how it may be possible to move forward with alternative new potent adjuvants. The article also contains brief summaries of recent experimental data obtained by the Finlay Adjuvant (AF) platform, based on proteoliposomes (PL), PL-derived cochleates (Co), 
and non PL-derived Co for the development of prophylactic and therapeutic vaccines.

\section{KEY FEATURES IN MODERN VACCINOLOGY LINKED WITH THE DEVELOPMENT OF ADJUVANTS IMMUNOPOLARIZED ADJUVANTS: CORNERSTONES TO DESIGN EFFECTIVE VACCINES}

An accurate classification of existing adjuvants has been difficult to achieve. This is due to their great diversity; in many cases the mechanism of action is still unknown (7). The most appropriate existing classifications include two main groups. The first is defined as facilitators of signal 1 , signal 2, and/or signal 3 (8); these signals are able to induce an immune response $(2,9)$. In accordance with these functional characteristics, adjuvants can facilitate T-cell receptor (TCR) engagement, antigen capture by dendritic cells (DC) at the inoculation site, and delivery to particular sites of the regional lymph nodes (signal 1) co-stimulation, with the upregulation of soluble and membrane co-stimulatory signals (signal 2 ), and an inflammatory stimulus by activating Th cells (signal 3 ) via cytokines. The second group takes into account the role of adjuvants as immunopotentiators (IP) and/or delivery system (DS) (10). Nevertheless, we consider that the infected host requires a particular kind of immune response to protect itself against each infection. Consequently, we have included immunopolarization $(\mathrm{IPz})$ as a third category, which is totally independent of those defined above $(3,11)$. With the vast information available today on the role of MAMPs in the induction of immune responses and knowing the IPz properties of an adjuvant, it should be possible to tailor a vaccine to selectively induce the desired response against specific infections. It is now clear that different subsets of helper Tcells, such as Th1, Th2, Th3, Th9, Th17, and follicular Th (Tfh) and $T$ regulatory cells are part of the cell-mediated immune protection against different pathogens. Several adjuvants have been shown to be capable of stimulating more than one type of cell-mediated immune response. This concept has led us to introduce the idea that an IPz category is one that exhibits multiple stimulatory properties (activation of multiple TLRs), in different directions (activation of different T-cells subsets) of the immune response. Notably, adjuvants may share more than one of these properties (IP, DS, and IPz properties) (12). For example, the yellow fever vaccine YF-17D, one of the most effective vaccines available, stimulates innate and adaptive immunity through its ability to activate DCs via TLR-2, TLR-7, TLR-8, and TLR-9 (13). The triggering of multiple and simultaneous TLRs increases the production of cytokines IL-12 and IL-23, leading to synergistic activation of DCs, with enhanced and sustained Th1-polarizing capacity (14). Consistent with the stimulation of multiple facets of the immune response, it is well known that $\mathrm{CpG}$ dinucleotides redirect isotype production toward Th1, via TLR-9 and MyD88 (15). Recently, Mastelic et al. (16) have demonstrated that adjuvant/DSs like CpG oligonucleotides markedly increase germinal center Tfh cell and germinal center B cell responses in neonates. In other applications, immunopolarized adjuvant combinations could prove an important strategy in viral protection and cancer therapy, since TLR agonists may prime tumor cells to become targets for cytotoxic agents. In this context, use of a mouse model showed an increased protective efficacy of vaccination with a human immunodeficiency virus (HIV) envelope peptide following combination of three TLR agonists, TLR-2/6, TLR-3, and TLR-9 (17). Furthermore, in cancer immunity, it was observed that autologous tumor cells mixed with bacillus Calmette-Guerin (BCG) were of significant clinical benefit for patients with Stage II colon cancer (18).

\section{ADJUVANTS AND THE STIMULATION OF POLARIZED TH RESPONSES}

Most immunologists, particularly vaccinologists, consider antibodies the most important immune markers induced by vaccination (19). However, this categorization is not absolute, because if we eliminate T-cells, we certainly neither produce antibodies nor induce any long sustained protection. Often, however, antibody-mediated protection against a pathogen has been considered sufficiently effective, commensurate for vaccines to be licensed. Clearly, antibodies are more easily detected and quantified than cellular responses, indeed they are used to define the correlate of protection of several vaccines, based on antibody concentration, for example Haemophylus and pneumococcal vaccines or functional, such as bactericidal or opsonophagocytic in Neisseria vaccines. In the late 1980s, the concept that Th1 cells (cellular immunity) conferred protection against intracellular pathogens and Th2 cells (humoral immunity or antibody-mediated protection) conferred immunity against extracellular pathogens was formulated (20). In view of recent knowledge, this view is limited, especially as it has been demonstrated that antibodies participate in all aspects of the immune response, from protecting the host during the initiation of infection to later challenge. Additionally the hallmark of the Th2 (humoral) response in mice and humans is the production of specific $\operatorname{IgE}(21)$. Therefore, the induction of IgE is not synonymous with humoral immune responses. Cellular immune responses were primarily considered as those inducing only cytotoxic T-lymphocytes (CTLs) and later on as Th1 cells (21), required to induce a good CTL with memory response. The Th1 immune response also induces an antibody (humoral) response. The main functional antibodies are IgG2a or IgG2c, depending on the mouse strain, or IgG1 and IgG3 in humans. Their biological function is determined by their capacity to fix complement (IgG2a or IgG2c) and by Fc receptors (IgG1). In humans, IgG1, the most presented and long-lasting isotype in blood $\left(\sim 9 \mathrm{mg} \mathrm{mL}^{-1}\right.$; half-life of 21 days) is the dominant isotype in a Th1 cytokine response. It has also been assumed that the Th2 or humoral immune response induces neutralizing antibodies, while the Th1 response induces opsonophagocytic and bactericidal effector functions. However, it is necessary to introduce a cautionary note since all human IgG subclasses, including IgA, induce a similar level of neutralization (22). In mice, the antibody isotypes that bind best to $\mathrm{F} c \gamma$ receptors (such as IgG2a/2c) are also produced, in part, as a result of IFN- $\gamma$-mediated isotype switching of B cells (23). However, investigations have demonstrated that the production of antigen-specific IgE and specific IgG1 are not definitely correlated (24). The cytokine IL-4 appears not to be essential for IgG1 class switching, but plays a crucial role in IgE production (25). Consequently IgG1 in mice is not a predictor marker of Th2 immune response. Currently, the use of adjuvants has received much interest for allergen immunotherapy. The Th1-directing adjuvant, monophosphoryl lipid $\mathrm{A}\left(\mathrm{MPL}^{\circledR}\right)$, is now in clinical use in allergy vaccines formulated with the depot adjuvant L-tyrosine 
(26). The clinical efficacy of an ultrashort course of ragweed pollen allergen adsorbed to L-tyrosine plus MPL ${ }^{\circledR}$ (Ragweed MATA MPL) in reducing allergy symptoms in patients with seasonal allergic rhinitis has recently been shown (27). In the field of anti-viral immunity, virus-like particles (VLPs) are considered a potent vaccine platform, proven to be immunogenic and clinically effective. In order to enhance immune cell activation, the addition of TLR ligands and/or depot-forming adjuvants seems to be useful for the treatment of allergic rhinitis (28). In a prophylactic approach, the grass pollen allergen Phl p 5 was administered by a skin patch with or without the Th1-promoting CpG oligodeoxynucleotide 1826 as an adjuvant. The results indicated that the addition of $\mathrm{CpG}$ balanced the response and prevented allergic sensitization, i.e., IgE induction, airway inflammation, and expression of $\mathrm{T}$ helper 2 cytokines (29).

\section{SECRETORY IgA ANTIBODY: AN OLD FRIEND AND SENTINEL CAN BE BOLSTERED WITH MUCOSAL ADJUVANTS}

In the pathogenesis of infectious and contagious diseases, over $90 \%$ of pathogens enter or are established at mucosal surfaces. The antibody isotype IgA is the main antibody that confers mucosal protection. IgA is considered a non-inflammatory effector (30, 31). However, it is not clear whether this IgA effector function is linked with a Th3 or a Th2 cellular pattern (32). Recent work has demonstrated that IgG is capable of mediating active humoral protection in several mucosal locations, but the kinetics of the response is totally different to that of $\operatorname{IgA}(33,34)$. This is probably due to the mechanism of mucosal transportation; which is known to be passive for IgG (high blood concentration is required) and active for IgA. In addition, covalently conjugated polysaccharide vaccines, applied parenterally, contribute to the control of the infection by indirect protection by reducing the carriage rates (35) and herd immunity $(36,37)$, but salivary anticapsular IgA-levels seem to respond much better to natural boosting (38). Nevertheless, the influence of carriage over immunization is not clear. Another important set of observations is that not all locally induced antibodies are of the IgA isotype, in particular IgG has been found in several mucosal surfaces. For example, IgG concentrations exceed IgA in male and female genital tracts (39). This differential isotype distribution provides evidence for local immune origin, as distinct from the systemic compartment. One possible non-invasive method to detect mucosal, secretory IgA is through the analysis of saliva following salivary gland stimulation and IgA measurement. However, gut-associated and nasopharynxassociated lymphoid tissues do not contribute equally to the pool of memory/effector B cells that differentiate into mucosal plasma cells elsewhere in the body (40). Despite such problems, saliva remains an interesting biological fluid with great scientific and clinical potential (41). It has been recently stated that vaccine development initiatives should now focus on the development of mucosal vaccines, highlighting the need for the production of safe and potent adjuvants for mucosal delivery (42). At present, only a few attenuated oral whole-cell vaccines and nasal vaccines have been approved. Some of these have limited use (43). The rational design of mucosal adjuvants demands a better understating of the mucosal immune system and mechanisms governing its activation $(44,45)$. Consequently, several vaccine companies have been addressing these goals, but so far with limited or no success. Overall, more work is required to understand the mechanism of production of IgA and its role in mucosal protection. Searching for mucosal adjuvants could be an essential step in advancing the field of vaccinology.

\section{NEW STUDIES OF ADJUVANT-ANTIGEN VACCINE FORMULATIONS SHOULD ACCELERATE THE DEVELOPMENT OF VACCINES}

In vaccine development, the choice of antigen is essential. However, vaccine formulations coupled to the correct adjuvants might be decisive in developing an effective vaccine formulation against life-threatening and neglected infectious diseases. Many recent vaccine projects have faced the problem of antigenic variation. The diversity of antigens has been difficult to classify. Some microorganisms, for example Streptococcus pneumoniae and N. meningitidis, exhibit little antigenic variability within a host, but show extensive population-wide variation that can change in a given demographical niche and time (46). Antigenic variation over time can be rapid, as with the influenza virus, where a new vaccine is required every year, and HIV and Hepatitis $\mathrm{C}$ virus, where spontaneous mutations during viral replication make it impossible to select a single protective antigen for use in a vaccine For vaccinologists, searching for stable or cross-reactive antigens, the biophysical characterization of antigens, assessing how antigens and adjuvants interact, and formulating stability should be the basis of a systematic approach to the development of effective, safe, and inexpensive vaccines. Currently, the most used adjuvant in licensed products is Alum, which acts as a DS. The critical aspect in this type of formulation is antigen adsorption. Alternatively, adjuvants can be a complex of multiple substances: MF59, an oil-in-water emulsion composed of small droplets of squalene surrounded by a monolayer of non-ionic detergents is an example. However, the stimulatory capacities of these adjuvants are only present when they are fully formulated (47). GlaxoSmithKline (GSK, Belgium) has developed several adjuvants systems (AS) that combine classical adjuvants with immunomodulators specifically adapted to the antigen and the target population (48). AS04 (a combination adjuvant composed of MPL A (a TLR-4 ligand) adsorbed to Alum) is licensed for use, in GSK's Cervarix vaccine against human papilloma virus and the vaccine against hepatitis B virus (49). This formulation includes IP and DS properties. Currently, evidences in the work with AFCo1 and AFPL1 without Alum, with incorporated or coadministered antigens, have demonstrated that IP and IPz properties are contained in the same structure as endogenous adjuvants essential for their immunogenicity. Nevertheless, industry-quality adjuvant production and relevant antigen-adjuvant formulations should be considered as key factors by vaccine manufacturers and vaccine development programs. The following section looks at the Finlay adjuvants in more detail.

\section{FINLAY ADJUVANT PLATFORM: A DIFFERENT APPROACH FROM EXISTING ADJUVANT TYPES}

The Finlay Adjuvant (AF) platform consists of a series of proprietary adjuvants (50-55). They combine three constituents: (i) nanovesicles (PL) extracted from bacterial outer membranes that contain protective antigens (56-58), in addition to adjuvant components; (ii), PL-derived Co (microparticles), which conserve 


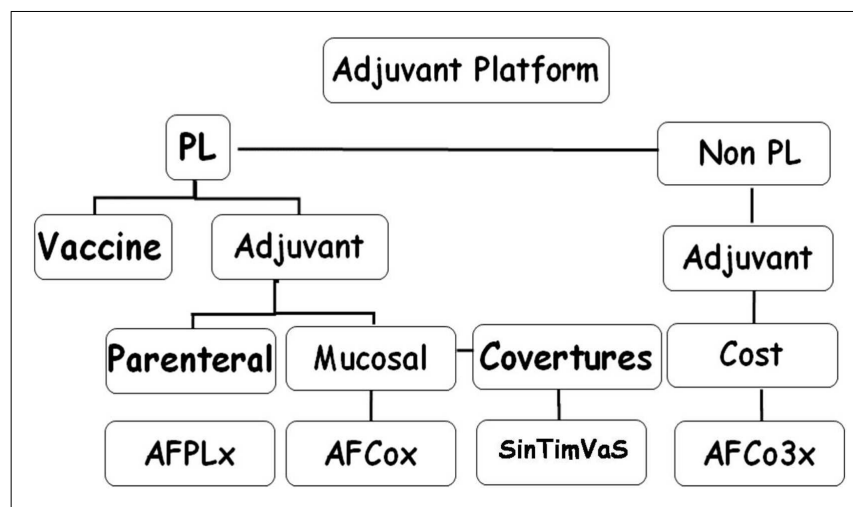

FIGURE 1 | Finlay adjuvant platform. PL, proteoliposome, nanovesicles extracted from bacterial outer membrane (OMV); AFPLx, adjuvant Finlay PLx extracted from different bacteria; AFCo (Cochleate)x obtained from PLx; STVS, single-time vaccination strategy; AFCo3, Co obtained from non-derived-PL structure.

the protective and adjuvant PL components; and (iii), non-PL derived Co (microparticles), with MAMPs as the main component (Figure 1).

\section{ADJUVANT FINLAY PROTEOLIPOSOME IN ALUM, INCREASES ITS STABILITY, REDUCES ITS PYROGENICITY, AND INDUCES Th1 POLARIZATION}

The adjuvant AFPL1 is a complex nano-structure consisting of vesicles extracted from the outer membrane of $N$. meningitidis serogroup B (B:4:P1,19,15:L3,7,9 strain). The vaccine properties of these outer membrane vesicles (OMVs) adsorbed onto alum gel was described and patented as part of the VA-MENGOC-BC ${ }^{\circledR}$ vaccine $(58,59)$. The first demonstration that AFPL1 induces a preferential Th1 polarization in humans was described by Lapinet et al. (60) and Pérez et al. (61). The presence of IFN $\gamma$ and IL-2 mRNAs was observed in peripheral blood mononuclear cells obtained from immunized subjects after in vitro challenge with AFPL1. AFPL1 also stimulated production of pro-inflammatory cytokines (TNF$\alpha$, IL-1 $\beta$, and IL- 8 ) and chemokines (MIP1- $\alpha$ and MIP1- $\beta$ ) by neutrophils. It was later demonstrated that AFPL1 stimulates specific CD4+ and CD8+ T cells and also elicits innate immunity activation inducing chemokines, pro-inflammatory cytokines, and co-stimulatory molecules. These products confirmed the adjuvant properties of the first AF described by Pérez et al. (62) and Pérez Martín et al. (51). AFPL1 can be adsorbed onto Alum; the degree of adjuvant adsorption is an important property that is related to the additional IP, DS, and IPz capacities of this preparation.

AFPL1 contains native lipopolysaccharide (LPS), PorB, traces of bacterial DNA, three synergistic MAMPs that interact with TLR-4, TLR-2, and TLR-9, respectively, as immunopotentiator molecules (Figure 2), which can be considered as their own endogenous adjuvants that are essential for vaccine immunogenicity. The nano-particle structure of the adjuvant, with negative and positive lipids and several glycoproteins, can package heterologous proteins and can be readily used as a vaccine-DS capable of enhancing the immunogenicity of exogenous protein antigens. In addition, studies in our laboratory have shown that the $\mathrm{IPz}$ effect is not limited to LPS (63). This combination vaccine may

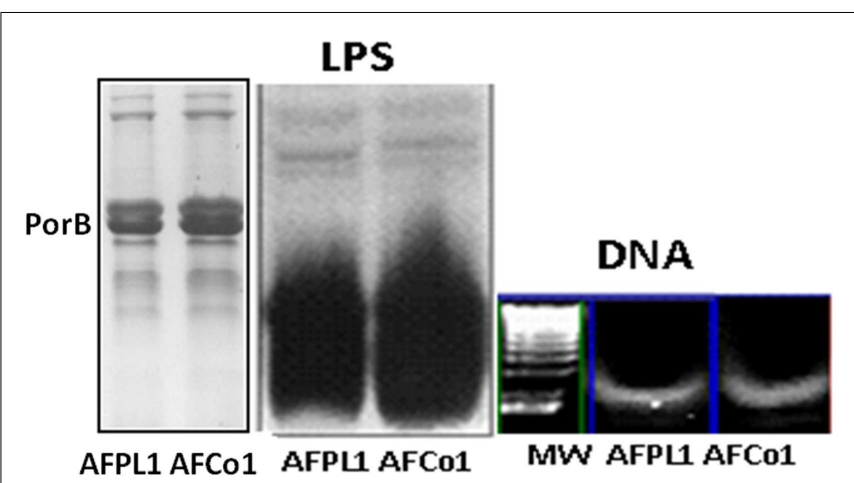

FIGURE 2 | Three main microbial-associated molecular patterns present in AFPL1 and AFCo1. Lipopolysaccharide (LPS) Porin B (PorB), and traces of bacterial DNA detected by SDS-PAGE stained with Coomassie blue for PorB and silver staining for LPS and agarose gel for DNA.

explain the preferential Th1 immune response, cross-priming, and in vivo CTL response characterized by the production of IL-12 and IFN $\gamma$ and delayed-type hypersensitivity. It might also explain the Th1 subclasses (IgG2a in BALB/c and IgG1 and IgG3 in human) and lack of IgE or IL-4/IL-5 production in mice and humans. Previous studies have shown that the OMV stimulate proinflammatory responses and induce immunoprotection against colonization or pathogenic challenge (64-66). For example, the Novartis MenB vaccine $\left(4 \mathrm{CMenB}\right.$, Bexsero $\left.{ }^{\circledR}\right)$, which received EU approval, includes three major antigens, identified by reverse vaccinology, and $25 \mu \mathrm{g}$ of detoxified OMV from strain NZ 98/254 $(67,68)$. Two other vaccines contain similar PL: the meningococcal vaccine, which includes a PL component, and received EU approval (68), and the malaria vaccine RTS,S/ASO1, developed by GSK, which includes PL as the liposome component of the AS01 adjuvant (69).

Stability is one of the requirements for any pharmaceutical formulation as well as low or absence of pyrogenicity. Therefore, adjuvants that contain native LPS should be monitored carefully. The adjuvant AFPL1 has LPS inserted in the structure and is never free. In addition, the consistency of GMP PL production at the Finlay Institute and the number of doses (more than $55 \times 10^{6}$ ) administered in adults and infants, as part of the National Immunization Program, guarantee that AFPL1 is considered a safe adjuvant per se. Further DS properties are introduced by the incorporation of AFPL1 onto alum gel. Importantly, this facilitates the commercialization process, since it increases safety and particle stability. In addition, it changes the suggested Th2 pattern of Alum to a Th1 pattern, increasing its stability for years, and reducing its pyrogenicity.

\section{THE FINLAY ADJUVANT COCHLEATE 1 DOES NOT REOUIRE ALUMINUM HYDROXIDE TO WORK FOLLOWING PARENTERAL AND MUCOSAL ADMINISTRATION}

AFCo1 is a PL-derived Co microparticle produced using different techniques (simple dialysis, rotary dialysis, or flow filtration) (70). Recently, in order to produce this adjuvant our laboratory has developed a closed cycle technology that is currently under expansion. Closed cycle technology permits the production of a sterile 
product. PL is dissolved in a buffer containing Tris $30 \mathrm{mmol} / \mathrm{L}$ and $1 \%(\mathrm{w} / \mathrm{v})$ sodium deoxycholate, $\mathrm{pH} 7.4$ to a final protein concentration of $1 \mathrm{mg} / \mathrm{mL}$. Then, formation buffer (Tris $30 \mathrm{mmol} / \mathrm{L}$, $\mathrm{CaCl}_{2} 10 \mathrm{mmol} / \mathrm{L}$, and $\mathrm{NaCl} 100 \mathrm{mmol} / \mathrm{L}, \mathrm{pH} 7.4$ ) is added. Excess detergent and calcium is removed by centrifugation at $3000 \times g$, $10 \mathrm{~min}$ with Tris buffer $(30 \mathrm{mmol} / \mathrm{L}, \mathrm{pH} 7.2)$ and stored at $4^{\circ} \mathrm{C}$. The Co formation is marked by the appearance of a white suspension. The efficiency of the process is estimated by protein quantities in the precipitate and the supernatant. The AFCol microparticles maintain the same IP, DS, and IPz properties of the AFPL1 precursor, and are stable. Alum is not required (Figures 2 and $\mathbf{3}$ ).

AFCo1 is an effective mucosal adjuvant in mice, when administered via different mucosal routes (nasal, oral, rectal, and vaginal) and combined with different antigens (ovalbumin, Ova; glycoprotein gD2 from Herpes Simplex Virus, HSV; bovine serum albumin, BSA; proteins, and peptides) (71, 72). AFCol administered by the nasal route induces systemic and mucosal (at local and distal sites) immune responses and total protection against HSV challenge (73).

AFCo1 is a microparticle with an approximate diameter of $11 \mu \mathrm{m}$. Although we predicted it would not work via the parenteral route, two intramuscular doses of AFCo1 plus Ova induced a similar systemic immune response of IgG, and subclass response (IgG1 and IgG2a), equivalent to three nasal doses in mice (Figure 4). This result suggests that the DS capacity of AFCo1-containing lipids and $\mathrm{Ca}^{2+}$ (known membrane perturbation and disruption agents) could take place through natural membrane fusion mechanisms, permitting interaction with several antigen-presenting cells without the requirement of internalization (74). Thus AFCo1 works via mucosal as well as parenteral routes. Currently, AFCo1 is in an advanced stage of clinical development with clinical trials on the horizon.

\section{FINLAY ADJUVANT PROTEOLIPOSOMES ADSORBED ONTO ALUM GEL OVERCOME THE Th2 PATTERN INDUCED BY ALLERGENS}

Allergens are inducers of a Th2 pattern, the hallmark of which is IgE production. Dermatophagoides siboney is a house dust mite, which in Cuba, is the main causative agent of allergy reactions. The Th2 response induced by Der s 1 and Der s 2 (the main $D$. siboney allergens) in Alum in unprimed mice was overcome by the formulation of AFPL1 adsorbed onto Alum. This induced $\operatorname{IgG} 2 \mathrm{a}, \mathrm{IFN} \gamma$, and caused the reduction of specific and total IgE $(50,75)$. Specific IgE was measured by passive cutaneous anaphylaxis in male rats challenged with sera from immunized mice with 3 allergen concentrations $(0.5 ; 1.25$, or $2.5 \mu \mathrm{g} / \mathrm{dose})$ and AFPL1 $(12 \mu \mathrm{g} / \mathrm{dose})$ in Alum. A reduction of the intensity of inflammation was 132, 42, and 37 times respectively (Figure 5A). When sera from immunized mice were diluted and retested, the positive dilutions observed were in the undiluted, 1:4, and 1:8 samples, respectively (Figure 5B). The efficiency of this formulation was also tested by the subcutaneous route in allergen unprimed and sensitized mice. This formulation has been concluded as satisfactory in preclinical toxicity and stability tests. A Phase I clinical trial using only three doses was approved by CECMED, the Cuban regulatory agency, and is in progress (DA-EC2012014). Overall, AFPL1 changes the Th2 behavior of $D$. siboney allergen in unprimed and sensitized mice and is a promising human vaccine.

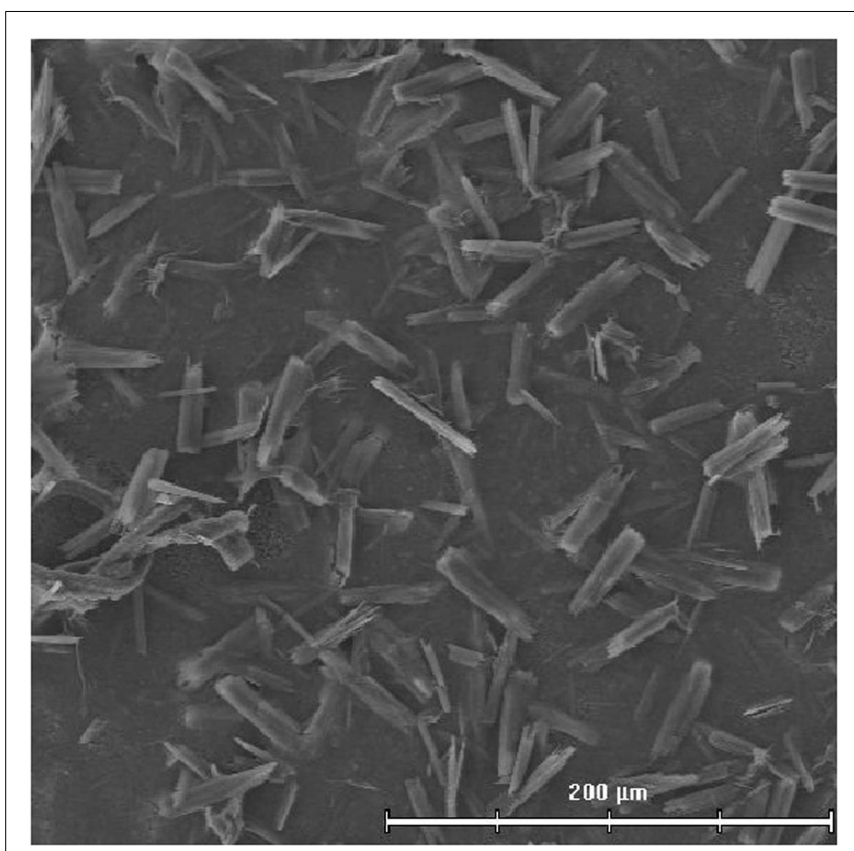

FIGURE 3 | Electron photograph of AFCo1 obtained by close cycle technology

\section{SINGLE-TIME VACCINATION STRATEGY TO INCREASE COVERAGE USING FINLAY ADJUVANTS}

Few vaccines are administered as a single dose. Also, it has been difficult to obtain a good immune response using non-living antigen vaccines as a single dose. With such vaccines, multiple doses are generally needed to provide sufficient stimulation of the immune system, and to achieve durable responses over time. Thus, a complete immunization schedule is mandatory for protection. The successful delivery of active vaccines depends amongst other factors on effective vaccine storage and distribution, including cold chain management. The cold chain aspect alone can account for $80 \%$ of the financial cost of a given vaccination program (76). The cost of the vaccination program is high in low-resource regions with poor vaccine affordability. Therefore, the development of new immunization strategies and procuring a single-dose vaccine are of pivotal importance.

Many studies combine nasal and/or oral routes with intramuscular immunizations, using the mucosal route as a priming dose and the parenteral route for the booster dose (traditional prime boosts spaced doses) or vice versa $(77,78)$. We have developed a novel immunization approach called singletime vaccination strategy (SinTimVaS) (79). In this approach a combination of two priming doses (one mucosal and one parenteral) is given simultaneously by different routes without the requirement for a subsequent boost. The use of potent adjuvants is a key factor in this novel strategy. González et al. (79) demonstrated that simultaneous vaccination such as intramuscular administration of AFPL1 and nasal administration of AFCol induced systemic and mucosal responses against $N$. meningitidis serogroup B. We have recently shown that SinTimVaS applications of tetanus toxoid or BSA combined with AF 

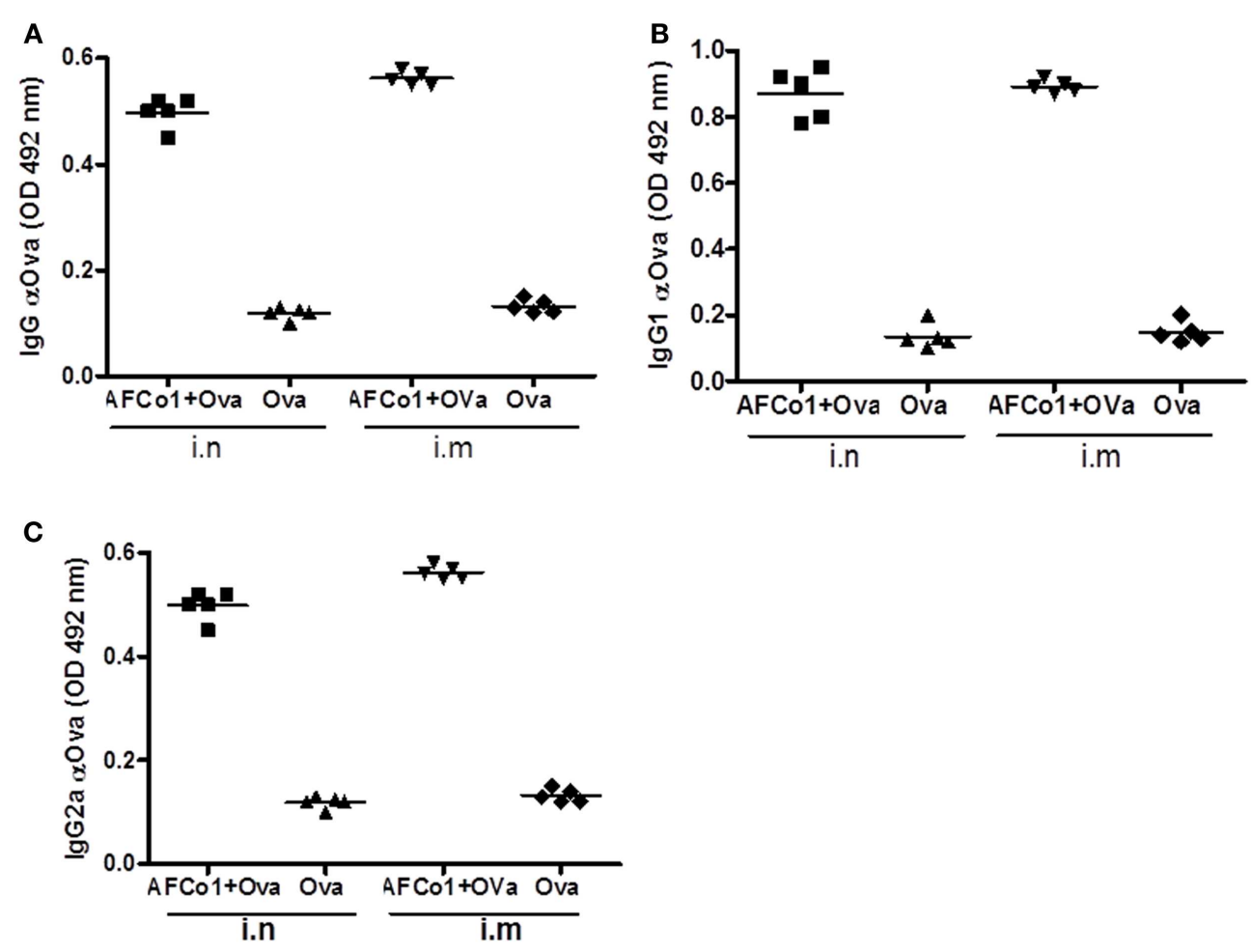

FIGURE 4 | Antibody response induced by AFCo1 plus Ovalbumin (Ova) by nasal (i.n) and intramuscular (i.m) routes. (A) IgG;

(B) IgG1; and (C), IgG2a. BALB/c mice were distributed in two

immunized groups and a control group. The first group was immunized with three i.n doses $(0,7,14$ days) of AFCo $1+$ Ova $(25 \mu \mathrm{g} / 20 \mu \mathrm{g}$ in

$25 \mu \mathrm{L}, 12.5 \mu \mathrm{L}$ through each nostril). The second was treated with two

i.m doses $(0,14$ days $)$ of AFCo $1+$ Ova $(12.5 \mu \mathrm{g} / 10 \mu \mathrm{g}$ in $50 \mu \mathrm{L}$ per

animal). The control received Ova i.n or i.m at 20 or $10 \mu \mathrm{g}$, respectively. Serum samples were taken 15 days after the last dose and antibody determination was carried out by ELISA. The figure shows the average and standard deviation of the mathematical relationship of values (OD) of two determinations in three independent experiments. The different $p$ denote significant differences according to a Tukey multiple comparison test $(p<0.05)$.

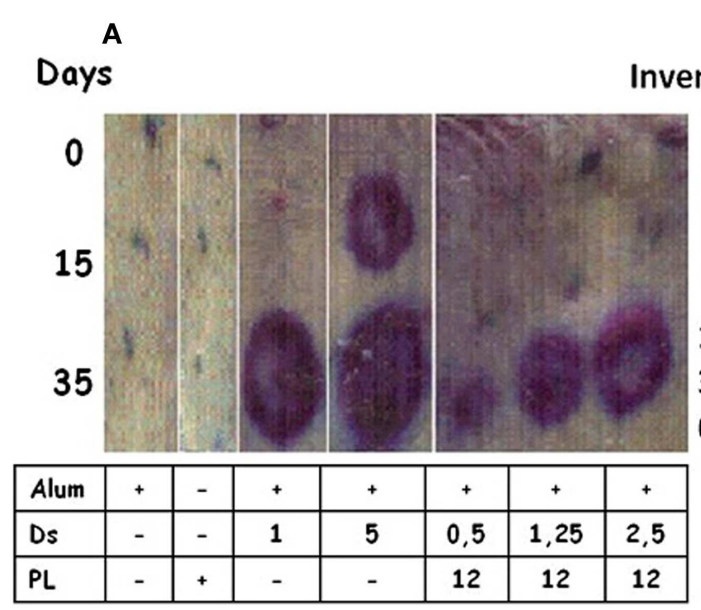

B

nverse of dilution

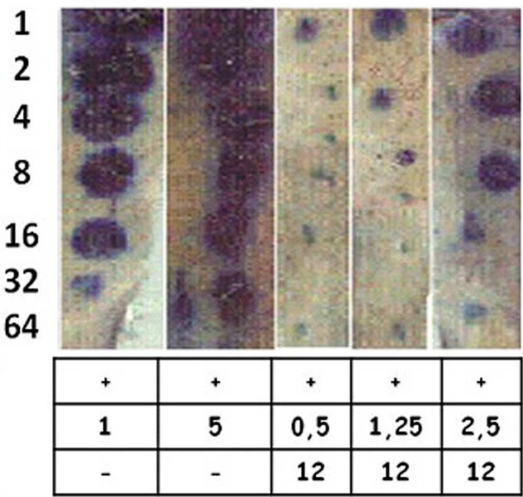

FIGURE 5 | Passive cutaneous anaphylaxis. Male rats were inoculated subcutaneously with $100 \mu \mathrm{L}$ of sera from mice immunized intramuscularly with two doses 15 days apart of Dermatophagoides siboney (Ds) allergen adsorbed onto aluminum hydroxide (Alum) at 1 or $5 \mu \mathrm{g}$ per dose, or adjuvanted with AFPL1 (PL at $12 \mu \mathrm{g}$ ) in Alum at Ds concentrations of
0.5-2.5 $\mu \mathrm{g}$ per dose. Controls included AFPL1 or Alum alone. Sera were prepared at 0, 15, and 35 days. After $48 \mathrm{~h}$, Evans Blue plus $1 \mathrm{mg}$ of Ds was inoculated intravenously. Then the rats were sacrificed and the skin was used to evaluate the density and diameter of the stain. (A) Shows the evaluation of undiluted sera and (B) the quantity of the specific IgE dilution in the sera. 
induced antigen-specific mucosal and systemic responses. Similar results were obtained using Ova as a weaker model antigen. This induced a similar systemic anti-Ova IgG response to two parenteral doses of AFPL1 plus Ova and three nasal doses of AFCo1 plus Ova (Figure 6A). Only AFCo1 plus Ova and SinTim$\mathrm{VaS}$ induced anti-Ova IgA (Figure 6B) and a memory response (Figure 6C). We also found that our immunization strategy not only works with AF, but also when cholera toxin is used as a mucosal adjuvant (Figure 6D). The strength of this strategy is that it can achieve high vaccine coverage, reducing the logistics and the number of follow-up and catch-up campaigns. It also induces similar systemic and mucosal immune responses. However, further studies using animal models as well as humans are needed to explain the immune mechanisms involved in this strategy.

\section{FINLAY ADJUVANTS CHANGE THE T-INDEPENDENCE PATTERN OF NON-COVALENTLY CONJUGATED POLYSACCHARIDES}

Encapsulated bacteria have an outer covering composed of capsular polysaccharides (Ps). The Ps are T-independent type 2 antigens (TI-2), based on their ability to stimulate antibody production in the absence of T-cell help (80). Thus, vaccination with TI-2 antigens elicits primarily IgM with limited class switching, affinity maturation, and immunological memory (81). Vaccines composed of Ps are immunogenic, provide protection in healthy adults and reduce the risk of invasive disease (82), but have low immunogenicity in children younger than 2 years of age (83). Also, these vaccines have demonstrated lack of booster responses to plain Ps challenge and an absence of affinity maturation of Ps specific antibodies (84). When Ps is covalently conjugated to a carrier protein, conferring the immunological attributes of the carrier on
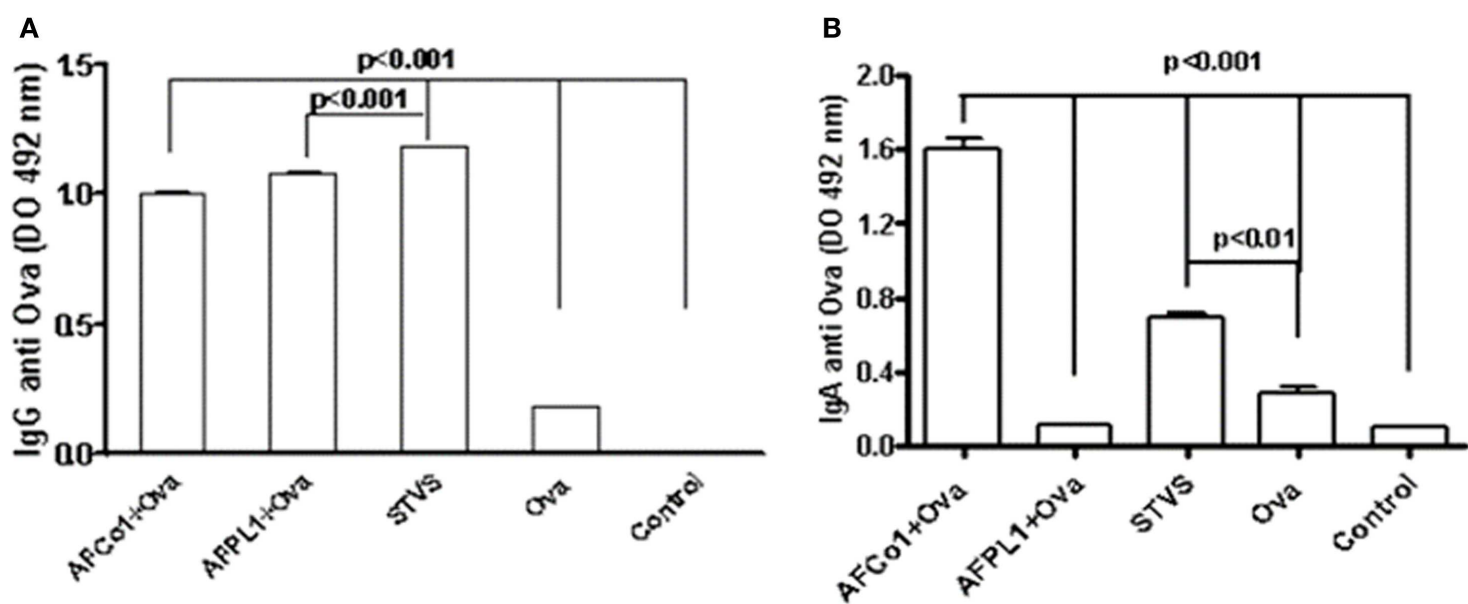

C

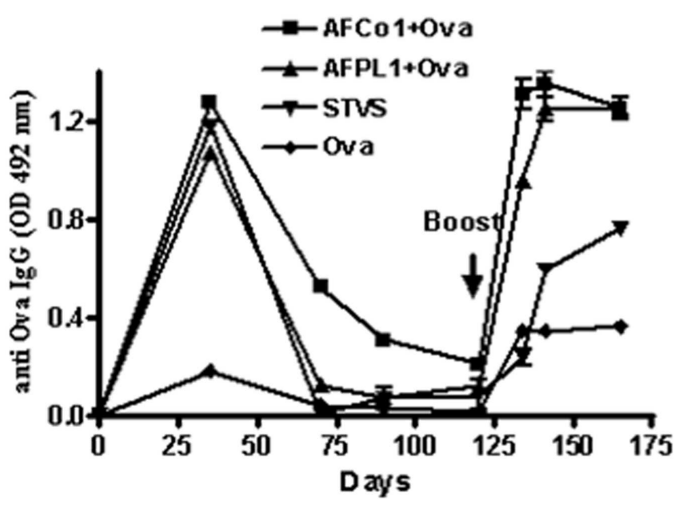

D

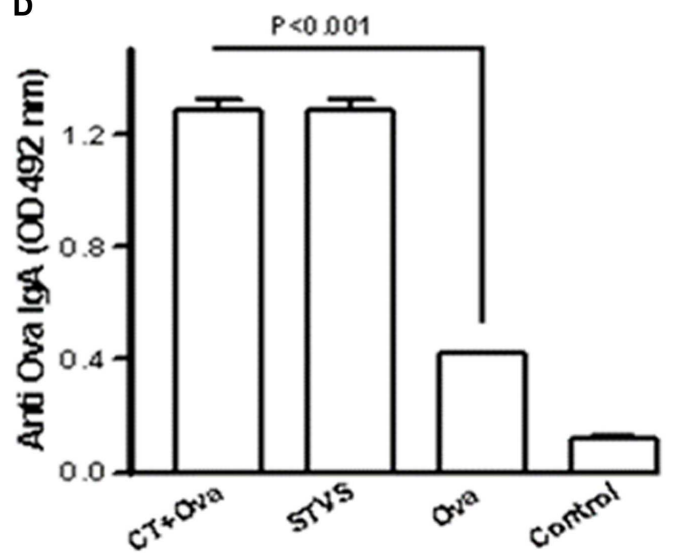

FIGURE 6 | Specific anti-Ova immune response induced by single-time vaccination strategy (SinTimVaS). BALB/c mice were immunized with: three i.n. doses $(0,7,14$ days $)$ of AFCo $1+$ Ova $(50 \mu \mathrm{g} / 25 \mu \mathrm{g}$ in $25 \mu \mathrm{L}$ per animal, $12.5 \mu \mathrm{L}$ through each nostril); two i.m. doses ( 0,14 days) of AFPL1 + Ova $(12.5 \mu \mathrm{g} / 10 \mu \mathrm{g}$ in $50 \mu \mathrm{L}$ per animal); both treatments at the same time in SinTimVaS and Ova as the control. Other groups were followed until specific IgG decreased and a booster Ova dose at day 125 was administered. Other groups using cholera toxin (CT) as the adjuvant instead of AFC01/AFPL1 were also evaluated. These were administered via the nasal route CT + Ova $(5 \mu \mathrm{g} / 50 \mu \mathrm{g}$ in $25 \mu \mathrm{L}$ per animal, $12.5 \mu \mathrm{L}$ through

each nostril) and simultaneously one intramuscular dose of CT + Ova $(5 \mu \mathrm{g} / 20 \mu \mathrm{g}$ in $50 \mu \mathrm{L})$ was administered. For anti-Ova IgG or IgA, serum samples at 21 days after the last dose were used. The determination was carried out by ELISA. Data were expressed as averages and standard deviation of OD of two determinations in three independent experiments. Specific Ova IgG (A); (B,D) specific Ova IgA; and (C) specific Ova IgG after a booster Ova dose. Significant differences between the means of different groups were determined by a Tukey multiple comparison test using Graph Pad Prism 4 software (Calif.). A p-value of $<0.05$ was considered statistically significant. 
the attached Ps, it elicits T-cell help for B cells, inducing largescale IgM to IgG switching of B cells to long-lived plasma cells or memory B cell development (85). Vaccination with conjugate vaccines increase the amount of specific IgG antibodies produced and increases the IgG:IgM ratio on repeated vaccination. The $\mathrm{IPz}$ effect of Finlay adjuvants has been tested against multiple protein antigens such as: merozoite surface proteins from Plasmodium falciparum (86), synthetic peptides and recombinant proteins from Streptococcus pyogenes (87). However, the incorporation of these adjuvants that possess the ability to trigger multiple TLR agonists, into plain Ps formulations could effectively avert the TI-2 of Ps. We have demonstrated that nasal immunization of AFCo1 plus Ps from N. meningitidis serogroup C induces PsC-specific mucosal and systemic immune responses (88).

Furthermore, studies with the Cuban bivalent vaccine (VAMENGOC-BC ${ }^{\circledR}$ ), which contains non-covalently conjugated PsC, showed that teenagers vaccinated in their infant life induced a significantly specific serogroup $\mathrm{C}$ response after a third dose of VA-MENGOC-BC ${ }^{\circledR}$ or to natural Neisseria challenge (89). We have also shown that subcutaneous immunization of AFPL1 plus Ps from N. meningitidis serogroup A (PsA) induced increased antibody affinity and a Th1 cytokine pattern after plain PsA booster (Figures 7A,B). In addition, Romeu et al. (90) demonstrated that a combined formulation of PLs from meningococcal serogroups $\mathrm{A}$ and $\mathrm{W}$ can stimulate cellular immunity and long-term memory cells against PsA, increasing affinity maturation after a plain Ps booster (90). The presence of several synergistic TLR agonists in the structure of these adjuvants influences anti-Ps antibody production, T-cell help, activation, and the proliferation of memory cells, opening new perspectives in the application of plain Ps antigens without the requirement of covalent conjugation. Therefore, the combination of Ps (conjugated or not) and Finlay adjuvants has the advantage of changing the TI-2 pattern of capsular Ps, which could have important implications for vaccinology. The mechanism of Ps presentation to T-cells described recently for Ps covalently conjugated vaccines (91) could possibly be extended to Ps-non-covalently conjugated formulations.

\section{THE APPLICATION OF AFCo3 AS AN IMMUNOPOTENTIATOR IN AQUACULTURE}

Aquaculture is one of the fastest growing economic activities in food production (92). One of the main challenges is to obtain a high-volume production of fish with the highest possible quality (93). Teleost fish, which mainly secrete IgM, display a strong innate immune response (94), but their adaptive immune response is relatively weak. In aquaculture, adjuvants and IPs in aquaculture have been used to improve the innate defense of fish and to promote healthy growth (95). The use of IPs constitutes a viable strategy to reduce losses from health problems in the aquaculture sector (96). Since the discovery of TLRs in fish, they have become of special interest in understanding host-pathogen interactions. LPS is known as one of the most potent IP in mammals. However, in fish, LPS is considered to have a low pro-inflammatory potential, probably due to the fact that the TLR- 4 genes found in similar aquatic organisms such as zebrafish do not recognize the mammalian agonist (97). However, cells and immune system components, both systemic and at the surface (intestinal and gill), are activated and mobilized in response to LPS (98). For example, immunization of the common carp (Cyprinus carpio) with LPS from Aeromonas hydrophila yielded an improved immunity and better survival (99). Grass carp (Ctenopharyngodon idella) injected intraperitoneally with LPS, outer membrane proteins or formalin killed cells from $A$. hydrophila induced a relative percent survival of $83.3,72.2$, and $55.6 \%$, respectively. This suggests that LPS and outer membrane proteins could be important in the development of vaccines against $A$. hydrophila in grass carp and other fish (100). Studies conducted by Nayak et al. (101) using the Indian major carp showed that LPS from three different gram-negative bacteria have IP potency (101). We have been working on the development of a novel microparticle adjuvant series called AFCo3a, which

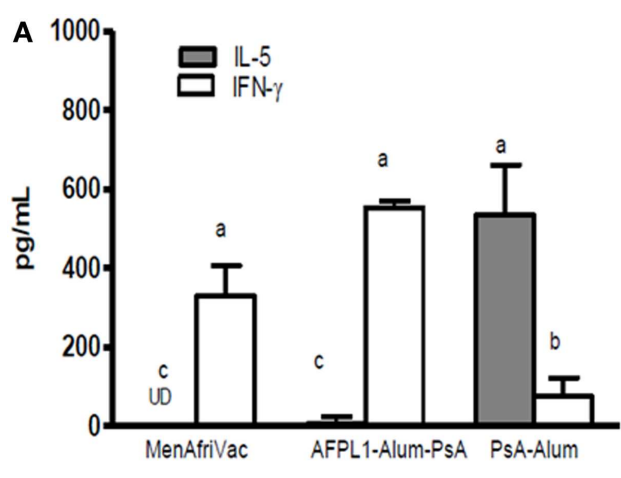

FIGURE 7 |Th1 cytokine profile and antibody affinity maturation after a plain PsA booster. Groups of mice received $5 \mu \mathrm{g}$ PsA adsorbed onto Alum or together with $5 \mu \mathrm{g}$ of AFPL1 or conjugate vaccine MenAfriVac $\AA$ via the subcutaneous route. Immunizations were performed twice, 21 days apart. A subcutaneous booster of plain PsA was performed 105 days after the last dose. Spleens from individual mice after the booster immunization were pooled within each group.

(A) Cytokine levels, measured by ELISA are expressed as $\mathrm{pg} / \mathrm{mL} \pm \mathrm{SEM}$.

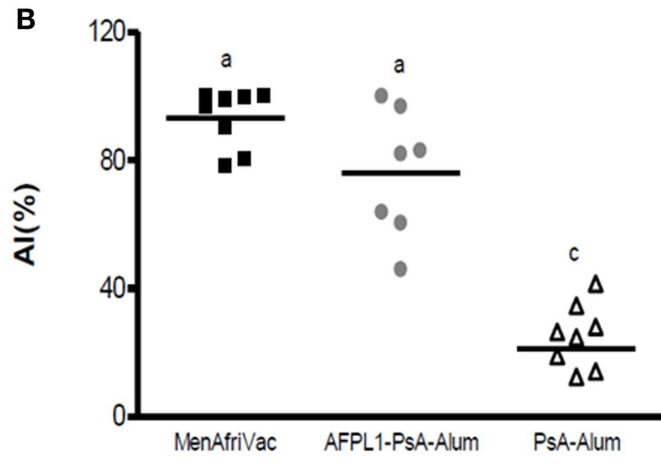

(B) affinity index (Al) was determined by avidity ELISA with $250 \mathrm{mM}$ sodium thiocyanate. The $\mathrm{Al}$, percentage of antibodies that remain bound to the antigen after treatment with the chaotropic agent, was calculated using the following formula: $\mathrm{Al}=$ titer $(\mathrm{NaSCN}+) /$ titer $(\mathrm{NaSCN}-)$. Results are expressed as the geometric mean of the affinity index (\%). Data were analyzed by one-way ANOVA followed by a Tukey's multiple comparison test. A p-value of $<0.05$ was considered statistically significant and is represented by different letters. 


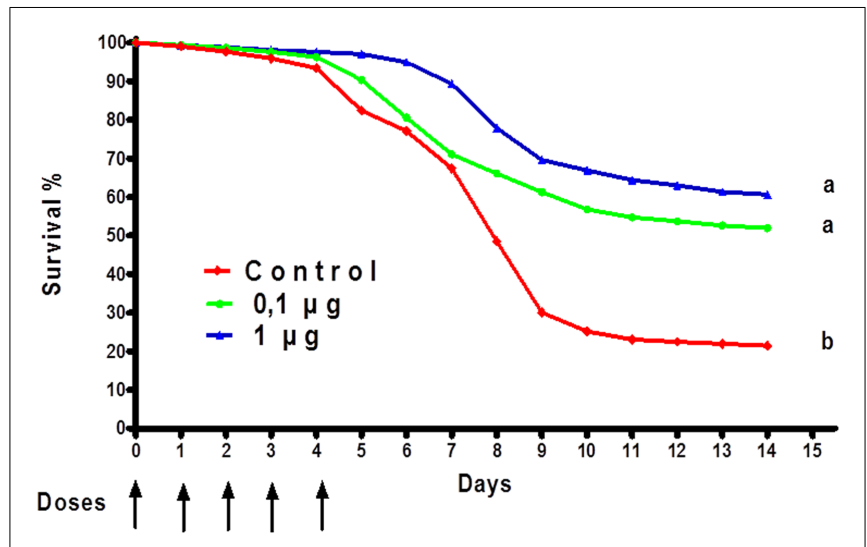

FIGURE 8 | Percentage of survival of Clarias gariepinus

immunopotentiated with AFCo3a. Oral treatments of AFCo3a mixed with the first daily food for five consecutive days. Survival was determined every day for 15 days. Statistical differences were determined by a

Kruskal-Wallis/Mann-Whitney U-test. A $p$-value of $<0.05$ was considered statistically significant and is represented by different letters.

contains LPS isolated from meningococcal bacteria (54). We are currently testing this preparation using the African catfish, Clarias gariepinus. Oral treatment of AFCo3a mixed with the first daily food administered for five consecutive days induced an improved survival rate compared with a control group (Figure 8). We also detected a significant $(p<0.05)$ increase in the production of IgM in fish treated orally with formalin-inactivated A. hydrophila, adjuvanted with AFCo3a. Our data suggests that oral application of potent IP-like Finlay adjuvants in aquaculture can be an effective and economical way to treat fish under intensive culture conditions. This is pertinent especially in view of the fact that the main losses in this industry are caused by excessive handling and high-density fish production.

\section{SUMMARY AND FINAL REMARKS}

With the increasing desire to obtain novel effective adjuvants to future vaccines this field is experiencing a renaissance. This paper illustrates the current state of affairs regarding the influence of existing adjuvants and terminologies that can properly guide adjuvant-vaccine research and formulation. It also summarizes how adjuvants are key factors for the development of future vaccines and the lessons learned from the Finlay Adjuvant platform. The key advantage of AFPL1 is its safety in humans, as a component of the prophylactic meningococcal vaccine. The recent development of the AFPL1 adjuvant as an allergen therapeutic vaccine has demonstrated effectiveness in reducing specific IgE and inducing preferential Th1 immune responses. Also, a new technology to produce PL or non-PL derived Co in a close cycle was developed, ensuring the production of sterile and scale-up products applicable not only to humans, but also in the veterinary field. The mucosal effectiveness of Co, their use in SinTimVaS permits increasing vaccination coverage and reducing campaign costs. The IPz properties of Co and PL to activate the innate immune response of fish and invertebrates could be a new field of application. The potential of the Finlay Adjuvants Platform to shape desired immune responses by stimulating multiple TLRs potentiating antigen-induced responses and providing not only prophylactic, but also therapeutic protection against infectious and non-infectious diseases was highlighted.

A better understanding of the mechanism of activation of the mucosal immune system, homing to effector sites and the role of mucosal IgA in mucosal protection is essential to provide mucosal protection against pathogens. More work should be addressed to find simple and affordable methods for the evaluation of cellular responses in the vaccination field, in so doing, cellular and mucosal vaccine protection correlates can be established. The applicability of AFPL1 as a nano-particle adjuvant to other vaccines and the clinical introduction of AFCo1, preferably with mucosal vaccine candidates or in SinTimVaS should be an essential step to consider. In addition, information gained in studies developed with nonconjugated-polysaccharides, provides opportunity to take rational approaches in the design of formulations capable of overcoming the T-independence of polysaccharides.

\section{ACKNOWLEDGMENTS}

We thank our collaborators and co-authors of our various papers and patents for contributing toward the development of the Finlay adjuvant platform. We are grateful to the many people involved with proteoliposome- and cochleate-related work through the years.

\section{REFERENCES}

1. Ramon G. Sur la toxine et sur I'anatoxine diphtheriques. Ann Inst Pasteur (1924) 38:1-10.

2. Ribeiro CM, Schijns VE. Immunology of vaccine adjuvants. Methods Mol Biol (2010) 626:1-14. doi:10.1007/978-1-60761-585-9 1

3. Pérez O, Batista-Duharte A, González E, Zayas C, Balboa J, Cuello M, et al. Human prophylactic vaccine adjuvants and their determinant role in new vaccine formulations. Braz J Med Biol Res (2012) 45(8):681-92. doi:10.1590/ S0100-879X2012007500067

4. Marrack P, McKee AS, Munks MW. Towards an understanding of the adjuvant action of aluminium. Nat Rev Immunol (2009) 9:287-93. doi:10.1038/nri2510

5. Lindblad EB. Aluminium compounds for use in vaccines. Immunol Cell Biol (2004) 82:497-505. doi:10.1111/j.0818-9641.2004.01286.x

6. Harandi AM, Medaglini D, Shattock RJ. Vaccine adjuvants: a priority for vaccine research. Vaccine (2010) 28(12):2363-6. doi:10.1016/j.vaccine.2009.12.084

7. Guy B. The perfect mix: recent progress in adjuvant research. Nat Rev Microbiol (2007) 5:505-17. doi:10.1038/nrmicro1681

8. Batista-Duharte A, Portuondo D, Zeppone I, Pérez O. An approach to local immunotoxicity induced by adjuvanted vaccines. Int Immunopharmacol (2013) 17(3):526-36. doi:10.1016/j.intimp.2013.07.025

9. Schijns VE. Immunological concepts of vaccine adjuvant activity. Curr Opin Immunol (2000) 12:456-63. doi:10.1016/S0952-7915(00)00120-5

10. O'Hagan DT, Valiante NM. Recent advances in the discovery and delivery of vaccine adjuvants. Nat Rev Drug Discov (2003) 2:727-35. doi:10.1038/nrd1176

11. Pérez O, Lastre M, Bracho G, del Campo J, Zayas C, Acevedo R, et al. Natural Neisseria derive proteoliposome and cochleate as potent vaccine adjuvants. Pharmacologyonline (2006) 3:762-4. doi:10.1016/j.ymeth.2009.03.025

12. Awate S, Babiuk LA, Mutwiri G. Mechanisms of action of adjuvants. Front Immunol (2013) 4:1-14. doi:10.3389/fimmu.2013.00114

13. Querec T, Bennouna S, Alkan S, Laouar Y, Gorden K, Flavell R, et al. Yellow fever vaccine YF-17D activates multiple dendritic cell subsets via TLR2, 7, 8, and 9 to stimulate polyvalent immunity. J Exp Med (2006) 203:413-24. doi:10.1084/jem.20051720

14. Napolitani G, Rinaldi A, Bertoni F, Sallusto F, Lanzavecchia A. Selected tolllike receptor agonist combinations synergistically trigger a $\mathrm{T}$ helper type 1-polarizing program in dendritic cells. Nat Immunol (2005) 8:769-76. doi:10.1038/ni1223 
15. Lin L, Gerth AJ, Peng SL. CpG DNA redirects class-switching towards "Th1like” Ig isotype production via TLR9 and MyD88. Eur J Immunol (2004) 34:1483-7. doi:10.1002/eji.200324736

16. Mastelic B, Kamath AT, Fontannaz P, Tougne C, Rochat AF, Belnoue E, et al. Environmental and $\mathrm{T}$ cell-intrinsic factors limit the expansion of neonatal follicular T helper cells but may be circumvented by specific adjuvants. J Immunol (2012) 189:5764-72. doi:10.4049/jimmunol.1201143

17. Zhu Q, Egelston C, Gagnon S, Sui Y, Belyakov IM, Klinman DM, et al. Using 3 TLR ligands as a combination adjuvant induces qualitative changes in T cell responses needed for antiviral protection in mice. J Clin Invest (2010) 120:607-16. doi:10.1172/JCI39293

18. Mosolits S, Nilsson B, Mellstedt H. Towards therapeutic vaccines for colorectal carcinoma: a review of clinical trials. Expert Rev Vaccines (2005) 4(3):329-50. doi:10.1586/14760584.4.3.329

19. Plotkin SA. Correlates of protection induced by vaccination. Clin Vaccine Immunol (2010) 17(7):1055-65. doi:10.1128/CVI.00131-10

20. Casadevall A. Antibody-mediated immunity against intracellular pathogens: two-dimensional thinking comes full circle. Infect Immun (2003) 71:4225-8. doi:10.1128/IAI.71.8.4225-4228.2003

21. Mosmann TR, Coffman RL. Th1 and Th2 cells: different patterns of lymphokine secretion lead to different functional properties. Ann Rev Immunol (1989) 7:145-73. doi:10.1146/annurev.iy.07.040189.001045

22. Delves PJ, Martin SM, Burton D, Roitt I. Essential Immunology, 11th ed. Blackwell Publishing (2006).

23. Abbas AK, Lichtman AH, Pillai S. Cellular and Molecular Immunology. 7th ed. W.B. Saunders Co (2012).

24. Okano M, Satoskar AR, Abe M, Harn DA Jr, Okano M, Nishizaki K, et al. Interleukin-4-independent production of Th2 cytokines by nasal lymphocytes and nasal eosinophilia in murine allergic rhinitis. Allergy (2000) 55(8):723-31. doi:10.1034/j.1398-9995.2000.00429.x

25. Yamatomo T, Okano M, Ono T, Nakayama E, Yoshino T, Satoskar AR, et al. Sexrelated differences in the initiation of allergic rhinitis in mice. Allergy (2001) 56:525-31. doi:10.1034/j.1398-9995.2001.056006525.x

26. Wheeler AW, Woroniecki SR. Immunological adjuvants in allergy vaccines: past, present and future. Allerg Int (2001) 50:295-301. doi:10.1046/j.14401592.2001.00230.x

27. Patel P, Holdich T, Fischer von Weikersthal-Drachenberg KJ, Huber B. Efficacy of a short course of specific immunotherapy in patients with allergic rhinoconjunctivitis to ragweed pollen. J Allergy Clin Immunol (2013). doi:10.1016/j.jaci.2013.05.032

28. Klimek L, Willers J, Schendzielorz P, Kündig TM, Senti G. Immunotherapy of allergic rhinitis without allergens? : New options for immunomodulation by vaccination with virus-like particles and CpG motifs. HNO (2013) 61:826-33. doi:10.1007/s00106-013-2761-9

29. Hessenberger M, Weiss R, Weinberger EE, Boehler C, Thalhamer J, Scheiblhofer S. Transcutaneous delivery of CpG-adjuvanted allergen via laser-generated micropores. Vaccine (2013) 31(34):3427-34. doi:10.1016/j.vaccine.2012.09. 086

30. Wolf HM, Eibl MM. The anti-inflammatory effect of an oral immunoglobulin (IgA-IgG) preparation and its possible relevance for the prevention of necrotizing enterocolitis. Acta Paediatr Suppl (1994) 396:37-40. doi:10.1111/j.16512227.1994.tb13240.x

31. Honorio-França AC, Launay P, Carneiro-Sampaio M, Monteiro RC. Colostral neutrophils express Fc $\alpha$ receptors (CD89) lacking $\gamma$ chain association and mediate noninflammatory properties of secretory IgA. J Leukoc Biol (2001) 69(2):289-96.

32. Fujihashi K, Kato H, Van Ginkel FW, Koga T, Boyaka PN, Jackson RJ, et al. A revisit of mucosal IgA immunity and oral tolerance. Acta Odontol Scand (2001) 59:301-8. doi:10.1080/000163501750541174

33. Westerman LE, McClure HM, Jiang B, Almond JW, Glass RI. Serum IgG mediates mucosal immunity against rotavirus infection. Proc Natl Acad Sci U S A (2005) 102:7268-73. doi:10.1073/pnas.0502437102

34. Lastre M, del Campo J, Cedré B, Valmaseda T, García L, Bracho G, et al. Mucosal IgA anti-lipopolysaccharide antibodies induced by 638 oral live attenuated candidate vaccine. Inmunología (2002) 21(1):3-9.

35. Ramsay ME, Andrews NJ, Trotter CL, Kaczmarski EB, Miller E. Herd immunity from meningococcal serogroup $\mathrm{C}$ conjugate vaccination in England: database analysis. BMJ (2003) 326:365.371. doi:10.1136/bmj.326.7385.365
36. Borrow R, Miller E. Long-term protection in children with meningococcal C conjugate vaccination: lessons learned. Expert Rev Vaccines (2006) 5(6):851-7. doi:10.1586/14760584.5.6.851

37. Pletz MW, Maus U, Hohlfeld JM, Lode H, Welte T. Pneumococcal vaccination: conjugated vaccine induces herd immunity and reduces antibiotic resistance. Dtsch Med Wochenschr (2008) 133(8):358-62. doi:10.1055/s-20081046719

38. Rodenburg GD, Sanders EAM, van Gils EJM, Veenhoven RH, Zborowski T, van den Dobbelsteen GPJM, et al. Salivary immune responses to the 7-valent pneumococcal conjugate vaccine in the first 2 years of life. PLoS One (2012) 7:e46916. doi:10.1371/journal.pone.0046916

39. Moldoveanu Z, Huang WQ, Kul-Havy R, Pate MS, Mestecky J. Human male genital tract secretions: both mucosal and systemic immune compartments contribute to the humoral immunity. J Immunol (2005) 175:4127-36.

40. Brandtzaeg P. Secretory immunity with special reference to the oral cavity. J Oral Microbiol (2013) 5:20401. doi:10.3402/jom.v5i0.20401

41. Brandtzaeg P. Do salivary antibodies reliably reflect both mucosal and systemic immunity? Ann N Y Acad Sci (2007) 1098:288-311. doi:10.1196/annals.1384. 012

42. Cabrera O, Cuello M, Lastre M, Romeu B, Balboa J, Zayas C, et al. The golden era of vaccine adjuvants. Expert Rev Vaccines (2011) 10(7):1007-9. doi:10.1586/erv.11.62

43. Brandtzaeg P. Induction of secretory immunity and memory at mucosal surfaces. Vaccine (2007) 25:5467-84. doi:10.1016/j.vaccine.2006.12.001

44. De Magistris MT. Mucosal delivery of vaccine antigens and its advantages in 325 pediatrics. Adv Drug Deliv Rev (2006) 58:52-67. doi:10.1016/j.addr.2006. 01.002

45. Neutra MR, Kozlowski PA. Mucosal vaccines: the promise and the challenge. Nat Rev Immunol (2006) 6:148-58. doi:10.1038/nri1777

46. Lipsitch M, O'Hagan JJ. Patterns of antigenic diversity and the mechanisms that maintain them. J R Soc Interface (2007) 4(16):787-802. doi:10.1098/rsif. 2007.0229

47. Calabro S, Tritto E, Pezzotti A, Taccone M, Muzzi A, Bertholet S, et al. The adjuvant effect of MF59 is due to the oil-in-water emulsion formulation, none of the individual components induce a comparable adjuvant effect. Vaccine (2013). 31:3363-9. doi:10.1016/j.vaccine.2013.05.007

48. Garçon N, Chomez P, Van Mechelen M. GlaxoSmithKline adjuvant systems in vaccines: concepts, achievements and perspectives. Expert Rev Vaccines (2007) 6(5):723-39. doi:10.1586/14760584.6.5.723

49. Duthie MS, Windish HP, Fox CB, Reed SG. Use of defined TLR ligands as adjuvants within human vaccines. Immunol Rev (2011) 239:178-96. doi:10.1111/j. 1600-065X.2010.00978.x

50. Lastre M, Pérez Martín OG, Labrada A, Bidot I, Pérez J, Bracho G, et al. Allergy Vaccine Composition, Production Method Thereof and Use of Same in Allergy Treatment. WO 03/094964 A1 and Granted by Cuban Office for Intellectual Property OCPI 22983 (2004).

51. Pérez Martín OG, Bracho G, Lastre M, Sierra G, Campa C, Mora N, et al. Method of Obtaining Cochlear Structures, Vaccine Compositions, Adjuvants and Intermediates Thereof. WO/2004/047805 and Granted by Cuban Office for Intellectual Property OCPI23313 (2008).

52. Pérez Martín OG, Lastre M, Rodríguez T, Mastroeni P, Bracho G, del Campo J. Proteoliposomes and its Derivatives as Adjuvant Inducers of Citotoxic Response and the Resultant Formulation. Granted by Cuban Office for Intellectual Property OCPI CU23420 (2009).

53. Pérez O, González E, Romeu R, del Campo J, Acevedo R, Lastre M, et al. Single Time Vaccination Strategy. EP2359850 (A1) (2011).

54. Pérez Martín OG, González E, Cabrera O, Zayas C, Sifontes S, Balboa J, et al. Cochleate with Only MAMP. Patent applied to Cuban Office for Intellectual Property OCPI CU/P/2011/123 (2011).

55. Pérez Martín OG, Romeu B, Lastre M, Zayas C, González E, Balboa J, et al. Adjuvants for Polysaccharide Vaccines. Patent applied to Cuban Office for Intellectual Property OCPI CU-P-2011-2002 (2011).

56. Sierra VG, Campa HC. Preclinical and clinical studies with the antimeningococcal vaccine BC: VA-MENGOC-BC ${ }^{\circledR}$. Rev Interferon Biotechnol. Special volume (1990).

57. Sierra VG, Campa HC, Valcárcel M. Vaccine against group B Neisseria meningitidis: protection trial and mass vaccination results in Cuba. NIPH Ann (1991) 14:195-210. 
58. Huergo Concepción C, Sierra Gonzalez VG, Gutiérrez Vázquez MM, Bisset Jorrin G, Garcia Imia LG, de la Caridad Puentes Rizo G, et al. Method of Producing Neisseria meningitidis B Vaccine, and Vaccine Produced by Method. Granted US Patent No. 5597572 (1997)

59. Sierra VG, Campa C, García L, Sotolongo F, Izquierdo L, Valcárcel M. Efficacy evaluation of the Cuban vaccine VA-MENGOC-BC ${ }^{\circledR}$ against disease caused by serogroup BNeisseria menigitidis. Proceedings of the 7th International Pathogenic Neisseria Conference. Berlin: Walter de Gruyter \& Co (1990). p. 129-34.

60. Lapinet JA, Scapini P, Calzetti F, Pérez O, Cassatella MA. Gene expression and production of tumor necrosis factor alpha, interleukin-1beta (IL-1beta), IL8, macrophage inflammatory protein 1alpha (MIP-1alpha), MIP-1beta, and gamma interferon-inducible protein 10 by human neutrophils stimulated with group B meningococcal outer membrane vesicles. Infect Immun (2000) 68(12):6917-23.

61. Pérez O, Lastre M, Lapinet J, Bracho G, Padrón J, Díaz M, et al. Immune response induction and new effector mechanisms possibly involved in protection of cuban anti-meningococcal BC vaccine. Infect Immun (2001) 69(2001):4502-8. doi:10.1128/IAI.69.7.4502-4508.2001

62. Pérez O, Lastre M, Cabrera O, del Campo J, Bracho G, Cuello M, et al. New vaccines require potent adjuvants like AFPL1 and AFCo1. Scand J Immunol (2007) 66:271-7. doi:10.1111/j.1365-3083.2007.01981.x

63. Rodríguez T, Pérez O, Menager N, Ugrinovic S, Bracho G, Mastroeni P. Interactions of proteoliposomes from serogroup B Neisseria meningitidis with bone marrow-derived dendritic cells and macrophages: adjuvant effects and antigen delivery. Vaccine (2005) 23:1312-21. doi:10.1016/j.vaccine.2004. 07.049

64. Muralinath M, Kuehn MJ, Roland KL, Curtiss R III. Immunization with Salmonella enteric serovar typhimurium-derived outer membrane vesicles delivering the pneumococcal protein PspA confers protection against hallenge with Streptococcus pneumoniae. Infect Immun (2011) 79:887-94. doi:10.1128/IAI. 00950- 10

65. Schild S, Nelson EJ, Camilli A. Immunization with Vibrio cholera outer membrane vesicles induces protective immunity in mice. Infect Immun (2008) 76:4554-63. doi:10.1128/IAI.00532-08

66. Chen DJ, Osterrieder N, Metzger SM, Buckles E, Doody AM, DeLisa MP, et al. Delivery of foreign antigens by engineered outer membrane vesicle vaccines. Proc Natl Acad Sci U S A (2010) 107:3099-104. doi:10.1073/pnas. 0805532107

67. Dull PM, McIntosh ED. Meningococcal vaccine development - from glycoconjugates against MenACWY to proteins against MenB - potential for broad protection against meningococcal disease. Vaccine (2012) 30(Suppl 2):B18-25. doi:10.1016/j.vaccine.2012.01.062

68. Novartis. Novartis Receives EU Approval for Bexsero ${ }^{\circledR}$, First Vaccine to Prevent the Leading Cause of Life-Threatening Meningitis Across Europe (2013). Available from: http://hugin.info/134323/R/1672036/543712.pdf

69. Agnandji ST, Lell B, Soulanoudjingar SS, Fernandes JF, Abossolo BP, Conzelmann C, et al. First results of phase 3 trial of RTS, S/AS01 malaria vaccine in African children. N Engl J Med (2011) 365:186375. doi:10.1056/ NEJMoal102287

70. Pérez O, Bracho G, Lastre M, Mora N, del Campo J, Gil D, et al. Novel adjuvant based on a proteoliposome-derived cochleate structure containing native lipopolysaccharide as a pathogen-associated molecular pattern. Immunol Cell Biol (2004) 82:603-10. doi:10.1111/j.1440-1711.2004.01293.x

71. del Campo J, Lastre M, Bracho G, Rodríguez T, Gil D, Zayas C, et al. Immunological evaluation of bacterial derived cochleate and proteoliposome as mucosal adjuvants. Vaccine (2006) 24(Suppl 2):50. doi:10.1016/j.vaccine.2005.01.119

72. del Campo JM, Zayas C, Romeu B, Acevedo R, González E, Bracho G, et al. Mucosal immunization using proteoliposome and cochleate structures from Neisseria meningitidis serogroup B induce mucosal and systemic responses. Methods (2009) 49:301-8. doi:10.1016/j.ymeth.2009.03.025

73. del Campo J, Lindqvist M, Cuello M, Bäckström M, Cabrera O, Persson J, et al. Intranasal immunization with a proteoliposomederived cochleate containing recombinant $\mathrm{gD}$ protein confers protective immunity against genital herpes in mice. Vaccine (2010) 28:1193-200. doi:10.1016/j.vaccine.2009.11.035

74. Gould-Fogerite S, Mannino RJ. Cochleates for induction of mucosal and systemic immune responses. In: O'Hagan DT editor. Vaccine Adjuvants in Methods in Molecular Medicine. Preparation Methods and Research Protocols. Totowa, NJ: Humana Press (2000). p. 179-96.
75. Lastre M, Pérez O, Labrada A, Bidot I, Pérez J, Bracho G, et al. Bacterial derived proteoliposome for allergy vaccines. Vaccine (2006) 24(Suppl 2):S2-5. doi:10.1016/j.vaccine.2005.01.110

76. Chen X, Fernando GJP, Crichton ML, Flaim C, Yukiko SR, Fairmaid EJ, et al Improving the reach of vaccines to low-resource regions, with a needle-free vaccine delivery device and long-term thermostabilization. J Control Release (2011) 152:349-55. doi:10.1016/j.jconrel.2011.02.026

77. $\mathrm{Lu} \mathrm{S}$. Heterologous prime-boost vaccination. Curr Opin Immunol (2009) 21:346-51. doi:10.1016/j.coi.2009.05.016

78. Ogwang C, Afolabi M, Kimani D, Jagne YJ, Sheehy SH, Bliss CM, et al. Safety and immunogenicity of heterologous prime-boost immunisation with Plasmodium falciparum malaria candidate vaccines, ChAd63 ME-TRAP and MVA ME-TRAP, in healthy Gambian and Kenyan adults. PLoS One (2013) 8(3):e57726. doi:10.1371/journal.pone.0057726

79. González E, Romeu B, del Campo J, Acevedo R, Lastre M, Zayas C, et al. Mucosal and systemic immune response against Neisseria meningitidis B induced by single time vaccination strategy. Vaccimonitor (2009) 18(2):73-5.

80. Weintraub A. Immunology of bacterial polysaccharide antigens. Carbohydr Res (2003) 338:2539-47. doi:10.1016/j.carres.2003.07.008

81. Jakobsen H, Jonsdottir I. Mucosal vaccination against encapsulated respiratory bacteria - new potentials for conjugate vaccines? Scand J Immunol (2003) 58:119-28. doi:10.1046/j.1365-3083.2003.01292.x

82. Jackson LA, Neuzil KM. Pneumococcal polysaccharide vaccine. 5th ed. In: Plotkin SA, Orenstein WA, Offit PA editors. Vaccines. Philadelphia: Saunders (2008). p. 569-604.

83. Pollard AJ, Perrett KP, Beverley PC. Maintaining protection against invasive bacteria with protein polysaccharide conjugate vaccines. Nat Rev Immunol (2009) 9:213-20. doi:10.1038/nri2494

84. Konradsen HB. Quantity and avidity of pneumococcal antibodies before and up to five years after pneumococcal vaccination of elderly persons. Clin Infect Dis (1995) 21:616-20. doi:10.1093/clinids/21.3.616

85. Poland GA. Prevention of meningococcal disease: current use of polysaccharide and conjugate vaccines. Clin Infect Dis (2010) 50(Suppl 2):S45-53. doi: $10.1086 / 648964$

86. Bracho G, Zayas C, Wang L, Coppel R, Pérez O, Petrovsky N. AFCo1, a meningococcal B-derived cochleate adjuvant, strongly enhances antibody and T-cell immunity against Plasmodium falciparum merozoite surface protein 4 and 5 . Malar J (2009) 27(8):35. doi:10.1186/1475-2875-8-35

87. Guilherme E, Postol S, Freschi de Barros F, Higa R, Alencar, Lastre M, Zayas C, et al. A vaccine against $S$. pyogenes: design and experimental immune response. Methods (2009) 49:316-21. doi:10.1016/j.ymeth.2009.03.024

88. Romeu B, González E, Zayas C, del Campo J, Acevedo R, Cuello M, et al. AFCol as nasal adjuvant of capsular polysaccharide from Neisseria meningitidis serogroup C induces systemic and mucosal immune responses. Scand J Infect Dis (2011) 43:809-13. doi:10.3109/00365548.2011.586648

89. Pérez O, Romeu R, del Campo J, Zayas C, Lastre M. Proteoliposome and polysaccharide-based meningococcal vaccine are immunogenic in infants and toddlers and primes for memory against serogroup $\mathrm{C}$ polysaccharide. WJV (2013) 3(2):77-87. doi:10.4236/wjv.2013.32012

90. Romeu B, Lastre M, García L, Cedré B, Mandariote A, Fariñas M, et al. Combined meningococcal serogroup A and W135 outer-membrane vesicles activate cell-mediated immunity and long-term memory responses against noncovalent capsular polysaccharide A. Immunol Res (2013). doi:10.1007/s12026013-8427-6

91. Avci F, Li X, Tsuji M, Kasper D. A mechanism for glycoconjugate vaccine activation of the adaptive immune system and its implications for vaccine design. Nat Med (2011) 17:1602-9. doi:10.1038/nm.2535

92. World Aquaculture. FAO Fisheries and Aquaculture Department. Technical Paper No. 500/1. Rome: FAO (2010). 105 p.

93. Davis CR, Okihiro MS, Hinton DE. Effects of husbandry practices, gender, and normal physiological variation on growth and reproduction of Japanese medaka, Oryzias latipes. Aquat Toxicol (2002) 60:185-201. doi:10.1016/S0166445X(02)00004-8

94. Tort L, Balasch JC, MacKenzie S. Fish immune system. A crossroads between innate and adaptive responses. Inmunología (2003) 22:277-86.

95. Dimitroglou A, Merrifield DL, Moate R, Davie SJ, Spring P, Sweetman J, et al. Dietary mannan oligosaccharide supplementation modulates intestinal microbial ecology and improves gut morphology of rainbow trout, 
Oncorhynchus mykiss (Walbaum). J Anim Sci (2009) 87:3226-34. doi:10.2527/ jas.2008- 1428

96. Traifalgar RFN, Corre VL, Serrano AE. Efficacy of dietary immunostimulants to enhance the immunological responses and vibriosis resistance of juvenile Paneus monodon. J Fish Aquat Sci (2013) 8(2):340-52. doi:10.3923/jfas.2013. 340.354

97. Iliev D, Roach J, MacKenzie S, Planas J, Goetz F. Endotoxin recognition: in fish or not in fish? FEBS Lett (2005) 579:6519-6528. doi:10.1016/j.febslet.2005.10. 061

98. Kadowaki T, Yasui Y, Nishimiya O, Takahashi Y, Kohchi C, Soma G, et al. Orally administered LPS enhances head kidney macrophage activation with downregulation of IL-6 in common carp (Cyprinus carpio). Fish Shellfish Immunol (2013) 34(6):1569-75. doi:10.1016/j.fsi.2013.03.372

99. Selvaraj V, Sampath K, Sekar V. Adjuvant and immunostimulatory effects of beta-glucan administration in combination with lipopolysaccharide enhances survival and some immune parameters in carp challenged with Aeromonas hydrophila. Vet Immunol Immunopathol (2006) 114:15-24. doi:10.1016/j. vetimm.2006.06.011

100. Jinhui S, Qingkui W, Zhiyi Q, Dongqing B, Jingfeng S, Xiuting Q. Effect of lipopolysaccharide (LPS) and outer membrane protein (OMP) vaccines on protection of grass carp (Ctenopharyngodon idella) against Aeromonas hydrophila. Israeli J Aquac Bamidgeh (2011) 63:8.

101. Nayak SK, Swain P, Nanda PK, Mohapatra D, Behera T. Immunomodulating potency of lipopolysaccharides (LPS) derived from smooth type of bacterial pathogens in Indian major carp. Vet Microbiol (2011) 151(3-4):413-7. doi:10.1016/j.vetmic.2011.03.021

Conflict of Interest Statement: The authors declare that the research was conducted in the absence of any commercial or financial relationships that could be construed as a potential conflict of interest.

Received: 17 July 2013; accepted: 10 November 2013; published online: 02 December 2013.

Citation: Pérez O, Romeu B, Cabrera O, González E, Batista-Duharte A, Labrada A, Pérez R, Reyes LM, Ramírez W, Sifontes S, Fernández N and Lastre M (2013) Adjuvants are key factors for the development of future vaccines: lessons from the Finlay adjuvant platform. Front. Immunol. 4:407. doi: 10.3389/fimmu.2013.00407

This article was submitted to Immunotherapies and Vaccines, a section of the journal Frontiers in Immunology.

Copyright (C) 2013 Pérez, Romeu, Cabrera, González, Batista-Duharte, Labrada, Pérez Reyes, Ramírez, Sifontes, Fernández and Lastre. This is an open-access article distributed under the terms of the Creative Commons Attribution License (CC BY). The use, distribution or reproduction in other forums is permitted, provided the original author(s) orlicensor are credited and that the original publication in this journal is cited, in accordance with accepted academic practice. No use, distribution or reproduction is permitted which does not comply with these terms. 